\title{
'Flavorfest' Strawberry
}

Kim S. Lewers ${ }^{4}$, Patricia R. Castro ${ }^{1}$, John M. Enns, Stan C. Hokanson' and Gene J. Galletta ${ }^{3}$

USDA-ARS, Genetic Improvement of Fruits and Vegetables Laboratory, Building 010A, BARC-W, 10300 Baltimore Avenue, Beltsville, MD 20705

David T. Handley

University of Maine Cooperative Extension, P.O. Box 179, Monmouth, ME 04259

\section{Andrew R. Jamieson}

Agriculture and Agri-Food Canada, Kentville Research and Development Centre, 32 Main Street, Kentville, NS B4N 1J5, Canada

\section{Michael J. Newell}

Wye Research and Education Center, University of Maryland, P.O. Box 169, Queenstown, MD 21658

Jayesh B. Samtani and Roy D. Flanagan Department of Horticulture, Hampton Roads AREC, Virginia Polytechnic Institute and State University, 1444 Diamond Springs Road, Virginia Beach, VA 23455

\section{Barbara J. Smith}

USDA-ARS, Thad Cochran Southern Horticultural Laboratory, 810 Highway 26 West, Poplarville, MS 39470

\section{John C. Snyder, John G. Strang, and Shawn R. Wright \\ Department of Horticulture, N-318 Agricultural Sciences Center, University of Kentucky, Lexington, KY 40546-0091}

\section{Courtney A. Weber}

School of Integrative Plant Science-Horticulture Section, NYSAES, Cornell University, 630 West North Street, Geneva, NY 14456

Additional index words. Fragaria $\times$ ananassa, breeding, disease resistance

'Flavorfest', a "June-bearing" or "shortday" strawberry (Fragaria $\times$ ananassa Duch. ex

\footnotetext{
Received for publication 1 Mar. 2017. Accepted for publication 17 July 2017

This project was funded by USDA-ARS Projects 8042-21220-254-00 and 6062-21430-002-00-D. Evaluations in Virginia were funded by VAES, VCE, and the College of Agriculture and Life Sciences at Virginia Tech.

We wish to thank the USDA-ARS Beltsville Research Farm Services for field and greenhouse support, and Lassen Canyon Nursery (Redding, CA) for propagation for final testing and release. Mention of trade names or commercial products in this publication is solely for the purpose of providing specific information and does not imply recommendation or endorsement by the U.S. Department of Agriculture or any of the other coauthors' institutions.

${ }^{1}$ Current address: University of Córdoba, Departamento de Genética, Campus de Rabanales Edificio C5 2 planta, 14071 Córdoba, Spain

${ }^{2}$ Current address: University of Minnesota, Department of Horticultural Science, 258 Alderman Hall, 1970 Folwell Avenue, Saint Paul, MN 55108 ${ }^{3}$ Deceased.

${ }^{4}$ Corrresponding author. E-mail: Kim.Lewers@ ARS.USDA.gov.
}

Rozier) cultivar, was introduced for propagation to nurseries in Dec. 2012 by the U.S. Department of Agriculture - Agricultural Research Service (USDA-ARS). 'Flavorfest' was selected for its high yield of flavorful large fruits and resistance to anthracnose fruit and crown rots (caused by Colletotrichum acutatum J.H. Simmonds). The large, bright red fruits appear distinctively plump throughout a long midseason, fruiting once a year from Maine through North Carolina. 'Flavorfest', with exceptional flavor and high yield, is recommended as an anthracnose-resistant cultivar for annual plastic-culture system and matted row production from Zones $4 \mathrm{~b}-8 \mathrm{a}$.

\section{Origin}

'Flavorfest' was derived from a crosspollination of two USDA-ARS selections, B759 by B786, planned in 1995 by the late Dr. Gene Galletta, USDA-ARS, Beltsville, MD. The pedigree is 10 generations deep (Fig. 1) and includes cultivars and breeding selections from New York, North Carolina, New Jersey, Tennessee, and Scotland. The pedigree is incomplete, in that the parentage of a New Jersey breeding selection, three generations back on the paternal side, is not available. The pedigree of 'Flavorfest' testifies to the value of a long history of cooperation among breeding programs and illustrates the merit of continuity of breeding efforts and the importance of preserving breeding program records, even (or especially) those programs that are no longer functioning.

Seedlings from the 1996 cross of B759 by B786, by Mr. John Enns, were screened for resistance to a five-race composite of Phytophthora fragariae var. fragariae in a greenhouse test at Beltsville during the winter of 1996-97 by Dr. Gene Galletta, Mr. John Enns, and USDA-ARS pathologist Dr. John Maas, using the method of Scott et al. (1975). Surviving seedlings were transplanted in Spring 1997 to a field on the Beltsville Agricultural Research Center farm. The single seedling to become 'Flavorfest' was selected in 1998 as B1033 by Dr. Stan Hokanson and Mr. John Enns.

Plants clonally propagated from stolons or "runners" of B1033 were evaluated in observation plots in plasticulture in 1999 and a matted-row growing system in 2001. After selection in observation plots, the original mother plant of B1033, which had been maintained in a greenhouse, tested positive by grafting leaves onto virus-indicator strawberry plants, Fragaria vesca UC-5 and Fragaria virginiana UC-10 (Frazier, 1974a, 1974b). The tests were nonspecific, so it is not known how many or which viruses were present, but the presence of at least one virus during selection indicates 'Flavorfest' has at least a small degree of virus tolerance. Meristems from the original mother plant, B1033, were excised and grown in tissue culture and then in pots in a greenhouse before testing again for the presence of virus. The budline, B1033 Z22, showed no sign of virus in leaf grafting and was clonally propagated in a screenhouse. B1033 Z22 was selected in plasticulture in 2002 by Dr. Kim Lewers and Mr. John Enns for further evaluation. It is interesting that 'Flavorfest' was evaluated by three successive breeders in the USDA-ARS Beltsville breeding program, further illustrating the value of continued support of a breeding program through funding and personnel, as only the support scientist, Mr. John Enns, was present through the entire selection history of 'Flavorfest'.

B1033 Z22 was evaluated at Beltsville with other selections and cultivars each year from 2002 through 2006 in plasticulture and matted-row systems, then only in plasticulture from 2007 through 2012. Evaluations were conducted in observation plots and replicated yield trials. In 2009, clones of B1033 Z22 were propagated and virus-tested negative by Lassen Canyon Nursery, Redding, CA, for evaluation at Beltsville and multiple other locations as B1033 L from 2011 and 2012. B1033 L was evaluated after 2012 as 'Flavorfest'.

\section{Technical Description}

Plants. 'Flavorfest' produces a mediumdense upright plant with numerous long petioles. Petioles are light green with 


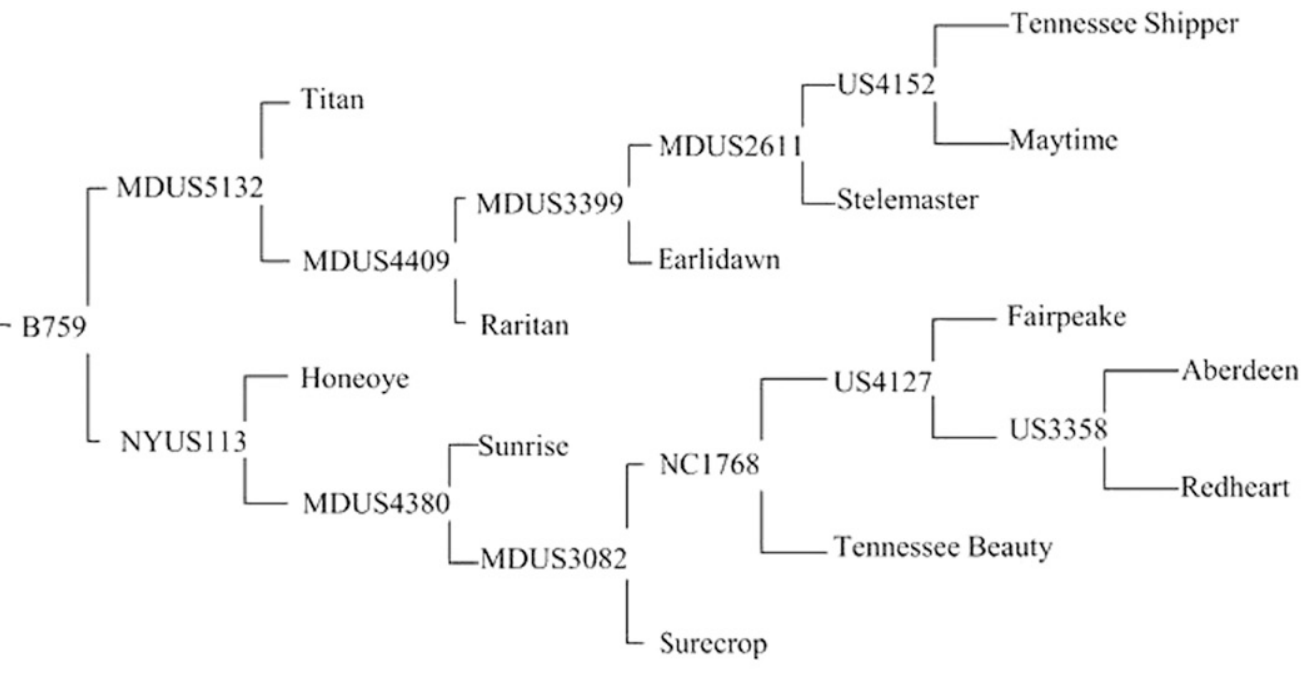

Flavorfest (B1033)

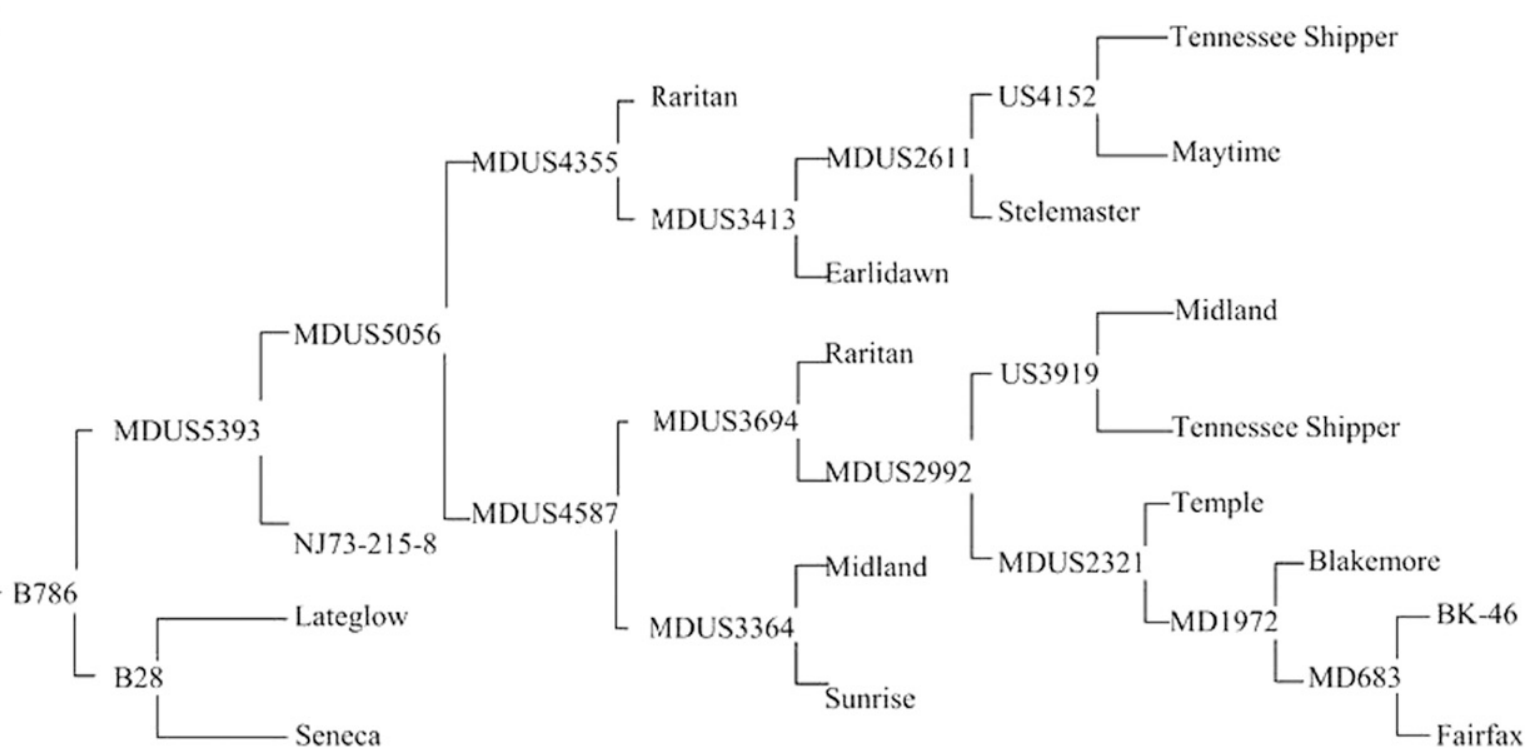

Fig. 1. Pedigree of 'Flavorfest' strawberry, released in Dec. 2012, by the USDA-ARS, from the Beltsville Agricultural Research Center, Beltsville, MD. Seed parents are represented above pollen parents.

brownish-red streaks, a fairly deep stem groove, and perpendicular hairs of low- to mid-density. Leaves are uniformly comprised of three leaflets. Leaf bracts are not common; however, when present, they can range from one or two leaflets to one or two cupped stipules and occur within $10 \mathrm{~cm}$ of the leaf origin. Leaf serration begins one-quarter to one-third from the base of the terminal leaflet with the terminal leaflets having between 26 and 36 serrations. They are dentate, medium in length, and uneven in size, with the terminal leaflet tipped shorter and smaller than adjacent leaflets. Individual leaves are slightly folded to open, medium green in color, with the leaflet tips being cupped. The terminal leaflet base occurs at about a $45^{\circ}$ angle. The interveinal lamina is smooth to slightly rugose. Stolons are medium red dorsally where exposed to the sun and green where shaded or on ventral surfaces.

Fruit. Fruit are large, firm, red, and glossy (Fig. 2). Achenes, which are flush to slightly beneath the fruit surface, are predominantly tan, but can be tan and red to completely red. Primary fruit are plump looking, globoseconic, with some fruits having slight ridges. Later fruit are more uniformly globose-conic. The calyx is at the fruit surface, and the fruits have no neck. The calyx can possess alternately reflexed and relaxed sepals to completely reflexed sepals. Interior flesh is orange-red at the distal end, with a lightorange ring around a slight cavity at the proximal end. Flesh is creamy, sweet, and aromatic.

Molecular markers. 'Flavorfest' was characterized with two simple sequence repeat molecular markers linked to repeat fruiting, ChFaM011 and FxaACA02I08C, using the methods of Castro and Lewers (2016). The reaction products obtained from ChFaM011 were 152 and 163 bp long; the $163 \mathrm{bp}$ product is associated with repeat fruiting in a mapping population using the cultivars Tribute and Honeoye (Castro et al., 2015). The reaction products from using FxaACA02I08C were 138, 143, 145, and $173 \mathrm{bp}$ long; the $145 \mathrm{bp}$ product is associated with repeat fruiting, as a dominant trait, in a mapping population using the cultivars Delmarvel and Selva (Castro and Lewers, 2016). 'Flavorfest' is not repeat fruiting, but will sometimes produce a few flowers and fruit in the fall of planting. Families from crosses between 'Flavorfest' and repeatfruiting genotypes have segregated for the repeat-fruiting trait; progeny from crosses between 'Flavorfest' on once-fruiting genotypes have all been once fruiting.

\section{Evaluation}

Production systems at Beltsville. 'Flavorfest' was evaluated with other selections and cultivars on the Beltsville Agricultural Research Center farm on Rumford series, course-loamy, siliceous, thermic Typic Hapludults soils. Plantings were established in plasticulture production (Black et al., 2002) using raised beds with trickle irrigation $7 \mathrm{~cm}$ below the surface. The plasticulture system uses black plastic mulch, and six plant 

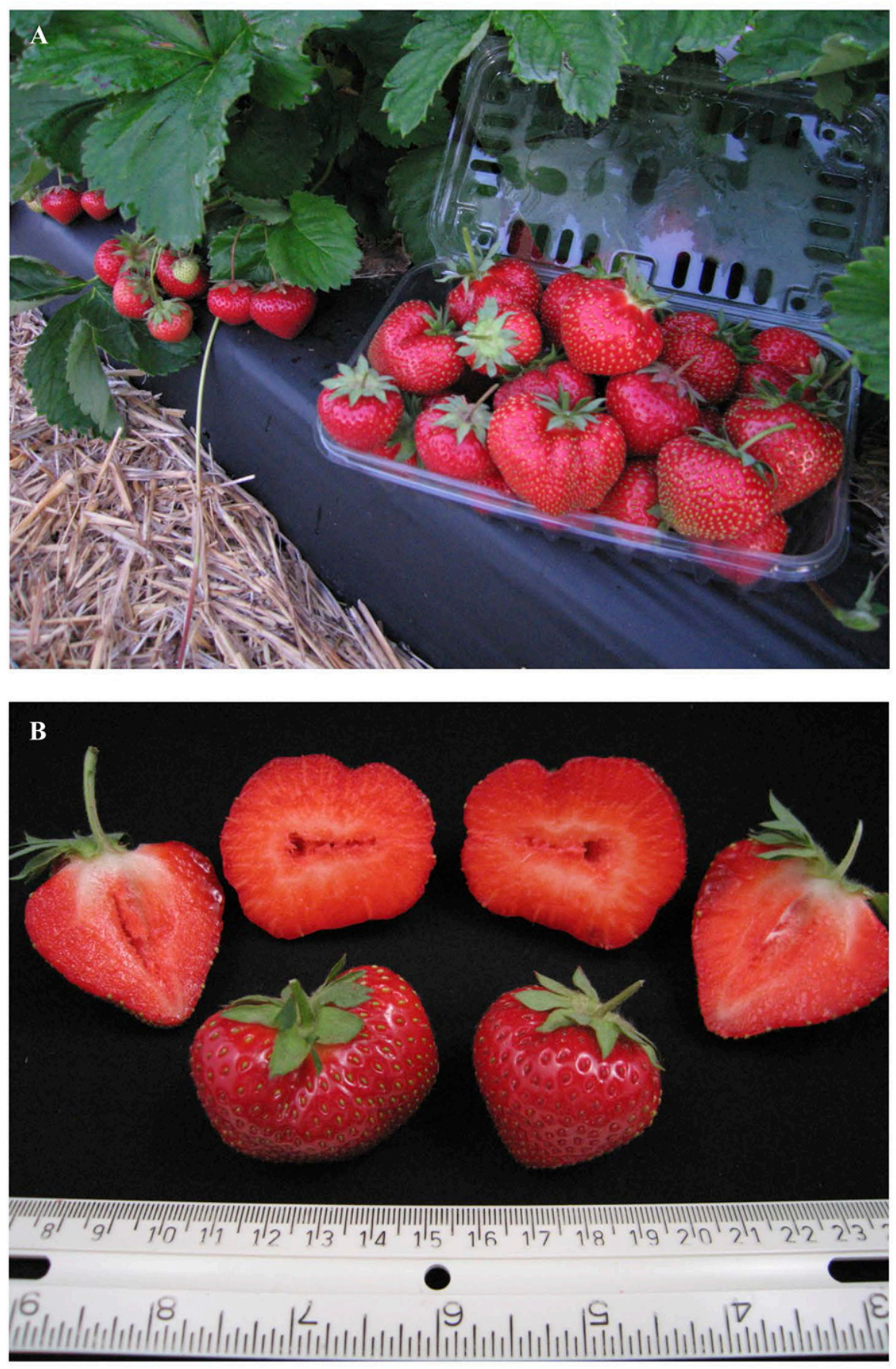

Fig. 2. 'Flavorfest' strawberry fruit, produced in plasticulture at the USDA-ARS, Beltsville Agricultural Research Center, Beltsville, MD.

plots were established in August before each evaluation year. Fertigation supplied nitrogen at a rate of $34 \mathrm{~kg} \cdot \mathrm{ha}^{-1} \mathrm{~N}$ per year as ammonium nitrate, potassium nitrate, or calcium nitrate on soils with existing high levels of $\mathrm{P}$ and moderate levels of $\mathrm{K}$. Calcitic lime was used to adjust soil $\mathrm{pH}$ to 6.3-6.5. No fungicides were used. Frost protection of spring flowers was provided from overhead impact-sprinklers at $1 \mathrm{~m}$ elevation when temperatures dropped below $1{ }^{\circ} \mathrm{C}$ and, after 2007, also from microsprinklers on $30.5 \mathrm{~cm}$ stakes (SuperNet Jr., Netafim, Fresno, CA) when temperatures dropped below $2{ }^{\circ} \mathrm{C}$.
Subjective evaluations of observation plots at Beltsville. Observation plots were evaluated annually in October after planting and again in April for plant stand, vigor, disease, and runner production, plus relative flowering and fruiting season in April. From 2010 forward, plots were rated for the specific plant diseases of powdery mildew [Podosphaera aphanis (Wallr.) U. Braun \& S. Takam], leaf blight [Phomopsis obscurans (Ellis \& Everh.) Sutton], and scorch [Diplocarpon earlianum (Ellis \& Everh.) F.A. Wolf] in addition to unspecified crown rot. During the fruiting season, observation plots were subjectively evaluated at the peak of their season for yield, size, appearance, symmetry, firmness, skin toughness (resistance to abrasion when rubbed with a thumb), skin color, flesh color, and flavor. From 2010 forward, plots also were rated for the specific diseases of anthracnose, botrytis fruit rot (Botrytis cinerea Pers.:Fr.), and unspecified soft rot and fruit degradation. Subjective scores for most traits could have ranged from 0.0 (worst) to 9.0 (best), with 7.0 being "cultivar quality." Scores of 6.5 for vigor, disease, or fruit quality were cause for concern, and scores of 6.0 or below were cause for rejection as a cultivar. Selections were not rejected for season scores, which also could have ranged from 0.0 (late) to 9.0 (early), nor for stolon production scores, which could have ranged from 0.0 (no stolons) to 5.0 (too many stolons), with 2.0 to 2.5 considered an optimal balance for both grower and nursery. Starting in 2010, three to five fruits and their juices also were measured once each year, from observation plots at the peak of the plot's production, for percentage soluble solids using a refractometer (Pocket refractometer PAL-1, ATAGO USA, Inc., Bellevue, WA). Means and ranges were determined in lieu of analyses of variance (ANOVAs) estimates due to the subjective nature of the measures, the broad range environmental conditions during measurement, and/or the number of measures $(n)$ for each genotype.

Replicated yield trials at Beltsville. Replicated yield evaluations were made in a randomized complete block design with one replication in each of three blocks. Plots were harvested twice weekly. For each plot at each harvest, decayed fruits were harvested into separate containers from fruits that showed no sign of decay. The containers were weighed separately. Yields were adjusted for plant stands. Ten randomly selected fruits from that container were weighed to obtain an average fruit weight for that plot and harvest. If fewer than 10 fruits were available, the average fruit weight was determined from the number available and was not adjusted for number or plot yield. Each year, separate ANOVAs were performed for yield, non-rotted yield, large fruit size, and average fruit size across harvests. Estimates of each year for total yield (g/plant), non-rotted yield (g/plant), average fruit size ( $\mathrm{g} /$ fruit), and largest average fruit size ( $\mathrm{g} /$ fruit) were used in a second ANOVA of means to compare 'Flavorfest' across multiple years with other locally grown cultivars: Earliglow, Chandler, Allstar, and Ovation.

\section{Yield}

'Flavorfest' yields were relatively high, nearly always ranking among the highestyielding cultivars tested each year (Fig. 3). The overall average yield from 12 years of testing was not significantly different from 'Allstar' but significantly higher than the cultivars Ovation, Earliglow, and Chandler.

\section{Season}

First harvest date of 'Flavorfest' at Beltsville ranged from 10 May 2012 to 28 May 2005. As 
determined by actual fruit yield each week through the harvest season, 'Flavorfest' is a midseason cultivar with a long season similar to that of 'Chandler' (Fig. 4). Of the 10 years both were harvested from replicated yield trials, 'Flavorfest' season came before that of 'Chandler' in 2013, 2014, and 2015, whereas 'Chandler' season came before that of 'Flavorfest' in 2006, 2009, and 2016. Interestingly, 'Flavorfest' harvest distribution had it classified as "early season" in 2 years, both of which had many frost events. In addition, each year, the morning of first harvest or the day before, the apparent season for new selections and cultivars also was determined subjectively in comparison with all other genotypes, including older cultivars with well-known seasons. The ratings were based on the amount of progression of ripening from flowers present to ripe fruit present. The ratings were subjective, from " 9 " (earliest with ripe fruit) to " 0 " (latest with just flowers). In this rating system, averaged overall years, the season for 'Flavorfest', at 5.0, indicated a slightly later season than determined by actual fruit harvest and was between that of the midseason cultivar, Chandler (6.0), and the midlate-season cultivar, Allstar (4.9). The season ratings for 'Earliglow' (7.8) and 'Ovation' (2.9) were consistent with their fruiting seasons. The year 2011 was representative of the relative seasons of the five cultivars.

\section{Fruit Size}

'Flavorfest' fruit size was similar to that of 'Ovation' and 'Allstar' and larger than that of 'Chandler' and 'Earliglow' (Fig. 5). Fruit size for a plot was measured at each harvest and averaged across 10 fruits and sometimes fewer. The average of all the plot $\times$ harvest averages was reported as the "average fruit size" for the year. The largest of the plot $x$ harvest averages was reported as the "large fruit size" for the year.

\section{Fruit Quality}

'Flavorfest' has excellent flavor, with an average subjective rating of 7.7, ranging from 7.0 to 8.0 (Table 1 ). The average flavor rating for the cultivar, Earliglow, known as an industry standard for flavor, also was 7.7 but with a wider range of 6.5-8.5. The average percentage soluble solids from observation plots for 'Flavorfest' was $7.7 \%$ and ranged from $6.4 \%$ to $10.0 \%$. The average percentage soluble solids for 'Earliglow' (8.3) ranged from $5.7 \%$ to $10.7 \%$. Firmness was reported subjectively by gently squeezing several individual fruits from observation plots each year (Table 1). 'Flavorfest' (7.6) was firmer than 'Chandler' (7.1) and not as firm as 'Allstar' (7.7). The lowest firmness ratings for the cultivars Flavorfest, Allstar, and Ovation were never below cultivar quality (7.0). Skin toughness was determined subjectively by gently rubbing a thumb against the skin of several individual fruits from an observation plot each year (Table 1). The average skin toughness was the same (7.4) for the cultivars Flavorfest, Earliglow, and Chandler. The lowest skin toughness rating was under cultivar quality (7.0) at least once for every cultivar.

\section{Disease Responses}

Fruit. The yearly averages for nonrotted fruit yield were analyzed separately from total yield to compare cultivars as candidates for growing without fungicides or fumigants. In these conditions, 'Flavorfest' non-rotted yields, around $81 \%$ of total yield, were among the highest and were similar to those of the cultivars Allstar and Ovation, as calculated from the estimated non-rotted yields and total yields from the ANOVAs of annual estimates (Fig. 3). This was partly because of the high total yields, as the percentage yield for the other cultivars, also were high. The most common fruit rot for 'Flavorfest' was botrytis fruit rot. The other midseason cultivar, Chandler, with $16 \%$ rotted fruit, was likely to have either botrytis fruit rot or an unspecified soft rot. The early-season cultivar, Earliglow, with only $10 \%$ rotted fruit, was most likely to have a problem with an unspecified rot. The midlate cultivar, Allstar, with $20 \%$ rotted fruit, was likely to have botrytis fruit rot, and the late-season cultivar, Ovation, with $14 \%$ rotted fruit, was likely to have an unspecified rot as seen with 'Earliglow'. This unspecified rot was not associated with any signs of pathogen and may be simple physiological degredation.

Plant. 'Flavorfest' was relatively resistant to foliar diseases. Subjective evaluation scores for foliar diseases included no susceptible ratings, although no fungicides were used. Averaged scores were 8.1 for powdery mildew, with individual plot ratings ranging from 7.5 to $8.5 ; 8.1$ for leaf scorch, ranging from 7.5 to 9.0 ; and 7.7 for leaf blight, ranging from 7.5 to 8.5 .

Subjective field evaluation scores of 'Flavorfest' plots for crown rot averaged 8.9, with any score under 9.0, a perfect score, being very rare. In a more objective evaluation using methods specifically to test for 
reaction to anthracnose crown rot, 'Flavorfest' was screened in a Mississippi greenhouse trial, in 2009 and twice in 2010, that included other commercial cultivars and inoculation with five Colletotrichum isolates representing three species (Chang and Smith, 2007; Lewers et al., 2007). Thirty days after inoculation of the aerial portion of plants, disease symptoms were rated based primarily on the size of lesions on the petiole with the most advanced symptoms. Significant culti- var $\times$ isolate interaction effects dictated separate ANOVAs by cultivar and by isolate (Table 2). Following inoculation with $C$. acutatum isolates Goff and CA1, no significant differences were found, and all cultivars averaged either resistant or intermediate. All the tested cultivars were susceptible to Colletotrichum gloeosporioides. There were no significant differences among cultivars to the Colletotrichum fragariae isolate CF75, although each rated either susceptible or intermediate. 'Flavorfest' plants were

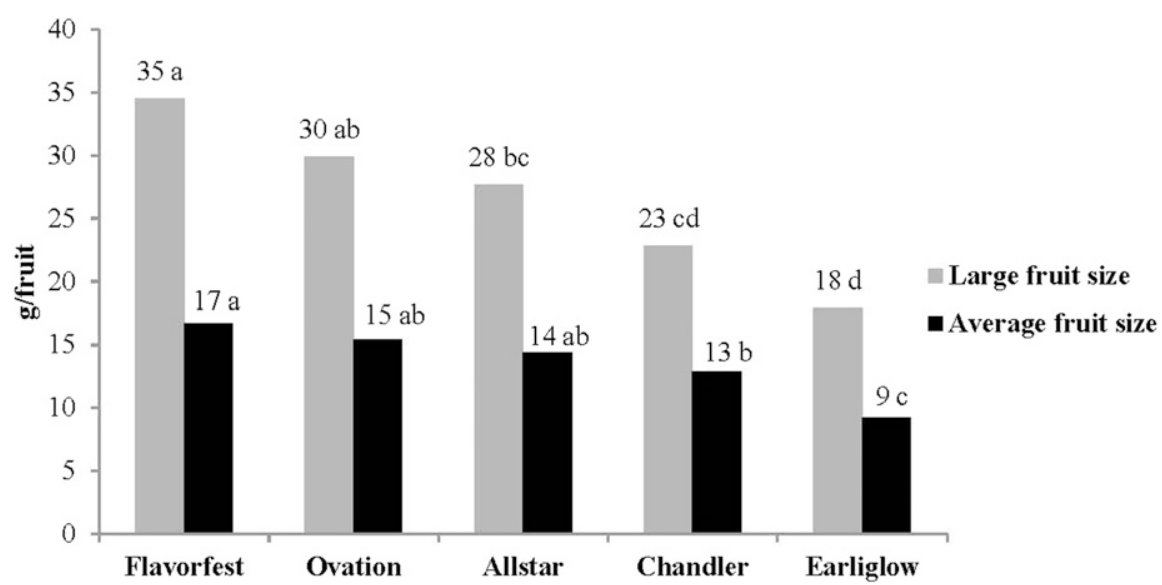

Fig. 5. 'Flavorfest' strawberry fruit size compared with other cultivars grown in plasticulture at the USDAARS Beltsville Research Center, Beltsville, MD, from 1999 through 2016. Ten randomly selected nonrotted fruits were weighed to obtain an average fruit weight for each plot and harvest. The average of all plot $\times$ harvest averages for a cultivar was reported as that cultivar's "average fruit size" for the year. The largest of those plot $\times$ harvest averages was reported as that cultivar's "large fruit size" for the year. Each year's average for average fruit size ( $\mathrm{g} /$ fruit), and largest average fruit size ( $\mathrm{g} /$ fruit) for each cultivar was used in an ANOVA.

Table 1. 'Flavorfest' strawberry fruit quality compared with other cultivars grown in plasticulture at the USDA-ARS Beltsville Research Center, Beltsville, MD. Flavor, firmness, and skin toughness were subjective ratings, agreed on by two researchers for each plot. Firmness was determined with a gentle hand squeeze. Skin toughness was determined by gently rubbing a thumb across the fruit. Averages and ranges for flavor, firmness, and skin toughness represent evaluations from 1999 through 2016. Percentage soluble solids measurements were started 2010, and derived from the hand-squeezed juice of three to five fruits using a "Pocket refractometer PAL-1" (ATAGO USA, Inc., Bellevue, WA) in the field. Means and ranges were calculated in lieu of ANOVA estimates due to the subjective nature of the measures, the broad range environmental conditions during measurement, and/or the number of measures $(n)$ for each genotype.

\begin{tabular}{|c|c|c|c|c|c|c|c|c|}
\hline \multirow[b]{2}{*}{ Cultivar } & \multicolumn{2}{|c|}{ Soluble solids (\%) } & \multicolumn{2}{|c|}{ Flavor } & \multicolumn{2}{|c|}{ Firmness } & \multicolumn{2}{|c|}{ Skin toughness } \\
\hline & Avg & Range & $\overline{\mathrm{Avg}}$ & Range & $\overline{\mathrm{Avg}}$ & Range & $\overline{A v g}$ & Range \\
\hline Earliglow & 8.3 & $5.7-10.7$ & 7.7 & $6.5-8.5$ & 7.3 & $6.0-8.0$ & 7.4 & $6.0-8.5$ \\
\hline Flavorfest & 7.7 & $6.4-10.0$ & 7.7 & $7.0-8.0$ & 7.6 & $7.0-8.0$ & 7.4 & $6.5-8.0$ \\
\hline Chandler & 7.3 & $5.0-8.6$ & 7.3 & $6.5-8.0$ & 7.1 & $6.5-7.5$ & 7.4 & $6.5-8.0$ \\
\hline Allstar & 7.4 & $6.1-8.6$ & 7.2 & $6.5-8.0$ & 7.7 & $7.0-8.5$ & 7.7 & $6.5-8.5$ \\
\hline Ovation & 8.3 & $7.6-10.0$ & 7.4 & $6.5-8.0$ & 7.4 & $7.0-8.0$ & 7.1 & $6.5-8.0$ \\
\hline
\end{tabular}

Table 2. Anthracnose disease scores of five strawberry cultivars following inoculation with five Colletotrichum isolates representing three Colletotrichum species (C. acutatum, isolates Goff and CA1, C. fragariae isolates CF63 and CF75, and C. gloeosporioides isolate CG162). Disease scores $\leq 2.0$ indicate a resistant response, $>2.0$ and $<4.0$ indicate an intermediate response, and $\geq 4.0$ indicate a susceptible response. Scores in bold text highlight resistant responses, and scores in italicized text indicate susceptible responses. Significant cultivar $\times$ isolate interaction effects dictated separate analyses by cultivar (rows) and by isolate (columns).

\begin{tabular}{llllllcr}
\hline Cultivar & Goff & CA1 & CF63 & CF75 & CG162 & Least significant difference (LSD) & $P>F$ \\
\hline Flavorfest & $\mathbf{0 . 9}$ & $\mathbf{0 . 3}$ & $\mathbf{1 . 2}$ & 3.1 & 6.0 & 1.0 & $<0.0001$ \\
Allstar & 3.0 & 3.0 & 3.4 & 4.1 & 4.4 & 1.7 & 0.3300 \\
Ovation & $\mathbf{1 . 5}$ & $\mathbf{1 . 7}$ & 3.1 & 4.9 & 5.4 & 1.4 & $<0.0001$ \\
Earliglow & $\mathbf{1 . 9}$ & 2.7 & 3.9 & 4.4 & 4.9 & 1.6 & 0.0040 \\
Chandler & 2.5 & 3.5 & 4.2 & 3.9 & 4.5 & 1.3 & 0.0200 \\
LSD & 1.7 & 2.4 & 1.5 & 1.2 & 1.1 & & \\
$P>F$ & 0.0700 & 0.0800 & 0.0004 & 0.0700 & 0.0200 & & \\
\hline
\end{tabular}

HortScience Vol. 52(11) November 2017

significantly more resistant to the $C$. fragariae isolate CF63 that the other cultivars.

Although the B1033 seedling was selected as resistant to a five-race composite of $P$. fragariae var. fragariae in a greenhouse test, it was later tested in greenhouses in Canada with individual races (Scott et al., 1975). No signs of infection were found on 'Flavorfest' roots when inoculated with Race A-3. This indicates that 'Flavorfest' likely carries the Rpf1 resistance allele (Haymes et al., 1997). There was some disease when roots were inoculated with Race A-5 (Montgomerie, 1967).

\section{Performance at Other Locations}

Acceptable to excellent performance has been reported from USDA Hardiness Zone Map Zone 8a through Zone 4b, although there are no reports of 'Flavorfest' evaluations outside these hardiness zones. 'Flavorfest' originated at Beltsville, in Zone $7 \mathrm{a}$, and excellent performance in terms of flavor and yield was reported from a Zone $7 \mathrm{~b}$ evaluation North Carolina (J. Ballington, personal communication). Evaluation in North Carolina and Virginia has been hampered by inadequate availability of plug plants, but 'Flavorfest' was reported in plasticulture cultivar trials in Virginia at Virginia Beach (Zone 8a), Chesapeake (Zone 8a), and Colonial Beach (Zone $7 \mathrm{~b}$ ) as having acceptable yield, the highest percentage soluble solids value, and most preferred flavor and sweetness in taste panels that included a total of 12 cultivars (Samtani and Flanagan, 2015). 'Flavorfest' received the highest possible flavor rating from $32 \%$ of panelists, compared with the standard cultivar for Virginia, Chandler, which received the highest flavor rating from only $4 \%$ of panelists (Samtani and Flanagan, 2015). 'Flavorfest' also was compared with 10 other cultivars in plasticulture at the Wye Research Center, Queenstown, MD, Zone 7b, in 2012 (Newell, 2013) and 2015 (Newell, 2016). In replicated comparisons in mattedrow production, 2015 and 2016, in Lexington, KY, Zone 6a, 'Flavorfest' was compared with 15 cultivars and performed well for yield, fruit size, flavor, attractiveness, firmness, and foliar disease resistance (Strang et al., 2016). In replicated tests in plasticulture near Geneva, NY, Zone 6a, 'Flavorfest' yield and fruit weight were among the highest in comparison with four other cultivars (Supplemental Table 1). In replicated matted row tests at Kentville, NS, also Zone 6a, 'Flavorfest' had the largest fruit and good stand establishment or "bed fill" (Supplemental Tables 2 and 3). Yield was comparable to two of the three other cultivars evaluated in 2011 and lower than the three other cultivars tested in 2012, although the yield varied considerably for 'Flavorfest' and the only other cultivar tested in both years. In matted-row production tests near Monmouth, ME, Zone 4b, in 2012, 'Flavorfest' had an acceptable yield of consistently large, attractive fruits with very good 
flavor and a relatively long season (Handley, 2013).

\section{Availability}

'Flavorfest' was increased by micropropagation from virus-indexed mother stocks, publicly released by the USDA Agriculture Research Service to nurseries on 5 Dec. 2012, without patent, and has been available for sale as bare-root dormant plants and as plug plants. 'Flavorfest' averaged about 15 daughter plants per mother plant in propagation by Lassen Canyon Nursery, Redding, CA, compared with 20 daughters per mother from 'Chandler' (Hanna Zeng, personal communication). Subjective observation scores at Beltsville confirm that 'Flavorfest' produces fewer runners, with an average score of 2.0, compared with 'Chandler', with an average score of 3.2. A score of 2.0 to 2.5 , on a scale of 0.0 (no runners) to 5.0 (too many runners), is considered a good balance. Strong runner production is valued by matted-row growers and by nurseries propagating plants for sale, but too many runners can lead to high labor expenses for removing runners in the plasticulture system. 'Flavorfest' is maintained by the USDA-ARS National Clonal Germplasm Repository at Corvallis, OR, as CFRA 2210.001 or PI 675459.

\section{Literature Cited}

Black, B.L., J.M. Enns, and S.C. Hokanson. 2002. A comparison of temperate-climate strawberry production systems using eastern genotypes. HortTechnology 12:670-675.

Castro, P., J.M. Bushakra, P. Stewart, C.K. Weebadde, D. Wang, J.F. Hancock, C.E. Finn, J.J. Luby, and K.S. Lewers. 2015. Genetic mapping of dayneutrality in cultivated strawberry. Mol. Breeding 35:79-94.

Castro, P. and K.S. Lewers. 2016. Identification of quantitative trait loci (QTL) for fruit quality traits and number of weeks of flowering in the cultivated strawberry. Mol. Breeding 36: $138-156$.

Chang, P. and B.J. Smith. 2007. Response of 'Treasure' and 22 Florida strawberry genotypes to the anthracnose pathogens Colletotrichum acutatum, C. fragariae, and C. gloeosporioides. Proc. 2007 N. Amer. Strawberry Symp. p 69-73.

Frazier, N.W. 1974a. Detection of grafttransmissible diseases in strawberry by a modified leaf grafting technique. Plant Dis. Rptr. 58:203-207.

Frazier, N.W. 1974b. Six new strawberry indicator clones evaluated for the detection and diagnosis of twelve graft-transmissible diseases. Plant Dis. Rptr. 58:28-31.

Handley, D.T. 2013. Matted row strawberry variety trial results 2012.31 Oct. 2017. <https://extension. umaine.edu/highmoor/research/matted-rowstrawberry-variety-trial-results-2012/>.

Haymes, K.M., B. Henken, T.M. Davis, and W.E. Van de Weg. 1997. Identification of RAPD markers linked to a Phytophthora fragariae resistance gene (Rpf1) in the cultivated strawberry. Theor. Appl. Genet. 94:1097-1101.

Lewers, K.S., W.W. Turechek, S.C. Hokanson, J.L. Maas, J.F. Hancock, S. Serçe, and B.J. Smith. 2007. Evaluation of elite native strawberry germplasm for resistance to anthracnose crown rot disease caused by Colletotrichum species. J. Amer. Soc. Hort. Sci. 132:842849.

Montgomerie, I.G. 1967. Pathogenicity of British isolates of Phytophthora fragariae and their relationship with American and Canadian races. Trans. Br. Mycol. Soc. 50:57-67.

Newell, M.J. 2013. University of Maryland, Wye Research and Education Center, Strawberry Production Trials. Strawberry Twilight Meeting. Queenstown, MD. 29 May 2013.

Newell, M.J. 2016. University of Maryland, Wye Research and Education Center, Strawberry Variety Trials. Strawberry Twilight Meeting. Queenstown, MD. 25 May 2016.

Samtani, J. and R. Flanagan. 2015. Virginia strawberry cultivar trial. Strawberry School, Virginia Beach, VA. 23-24 Feb. 2015.

Scott, D.H., J.L. Maas, and A.D. Draper. 1975. Screening strawberries for resistance to Phytophthora fragariae with single versus a composite of races of the fungus. Plant Dis. Rptr. 59:207-209.

Strang, J., C. Smigell, and J. Snyder. 2016. Evaluation of strawberry varieties as matted rows. Fruit and vegetable 2016 annual research rpt PR-721. 
Supplemental Table 1. Courtney weber; 2012 replicated tests in plasticulture near Geneva, NY, Zone $6 \mathrm{a}$ Yield 5 foot row spacing $\times 0.5 \mathrm{ft}$ plant spacing, $17424 \mathrm{pl} / \mathrm{ac}$, $43037 \mathrm{pl} / \mathrm{ha}$.

\begin{tabular}{|c|c|c|c|c|c|c|c|c|c|c|c|c|}
\hline Obs & Genotype & Estimate 10 plant total yield $(\mathrm{g})$ & Standard error & DF & $t$ Value & $\operatorname{Pr}>|t|$ & Alpha & Lower & Upper & Ib/acre & $\mathrm{kg} / \mathrm{ha}$ & LetGrp \\
\hline$\overline{1}$ & Flavorfest & $3,060.74$ & 452.95 & 12.8 & 6.76 & $<0.0001$ & 0.05 & 2,081 & $4,040.47$ & 15,521 & 17,426 & $\mathrm{~A}$ \\
\hline 2 & Jewel & $2,368.25$ & 323.9 & 10.5 & 7.31 & $<0.0001$ & 0.05 & $1,651.45$ & $3,085.05$ & 11,851 & 13,305 & $\mathrm{AB}$ \\
\hline 3 & Seneca & $1,993.5$ & 323.9 & 10.5 & 6.15 & $<0.0001$ & 0.05 & $1,276.7$ & $2,710.3$ & 10,411 & 11,689 & $\mathrm{AB}$ \\
\hline 4 & Ventana & 1924.75 & 323.9 & 10.5 & 5.94 & 0.0001 & 0.05 & $1,207.95$ & $2,641.55$ & 10,147 & 11,392 & B \\
\hline 5 & Clancy & $1,901.75$ & 323.9 & 10.5 & 5.87 & 0.0001 & 0.05 & $1,184.95$ & $2,618.55$ & 10,059 & 11,293 & B \\
\hline
\end{tabular}

\begin{tabular}{lrcccc}
\hline Source & DF & Sum of squares & Mean square & $F$ value & $\operatorname{Pr}>F$ \\
\hline Model & 4 & $2,935,664$ & $733,916.1$ & 1.74 & 0.2018 \\
Error & 13 & $5,491,791$ & $422,445.5$ & & \\
Corrected total & 17 & $8,427,456$ & & & \\
\hline
\end{tabular}

\begin{tabular}{|c|c|c|c|c|c|c|c|c|c|c|}
\hline \multicolumn{11}{|l|}{$\mathrm{g} /$ fruit } \\
\hline$\overline{\mathrm{Obs}}$ & Genotype & Estimate (g/fruit) & Standard error & $\mathrm{DF}$ & $t$ value & $\operatorname{Pr}>|t|$ & Alpha & Lower & Upper & LetGrp \\
\hline$\overline{1}$ & Flavorfest & 14.65 & 1.154 & 13 & 12.7 & $<0.0001$ & 0.05 & 12.157 & 17.143 & $\mathrm{~A}$ \\
\hline 2 & Clancy & 14.15 & 0.816 & 13 & 17.34 & $<0.0001$ & 0.05 & 12.3872 & 15.9128 & A \\
\hline 3 & Seneca & 11.025 & 0.816 & 13 & 13.51 & $<0.0001$ & 0.05 & 9.2622 & 12.7878 & B \\
\hline 4 & Ventana & 10.75 & 0.816 & 13 & 13.17 & $<0.0001$ & 0.05 & 8.9872 & 12.5128 & B \\
\hline 5 & Jewel & 10.25 & 0.816 & 13 & 12.56 & $<0.0001$ & 0.05 & 8.4872 & 12.0128 & B \\
\hline
\end{tabular}

\begin{tabular}{lrcccc}
\hline Source & DF & Sum of squares & Mean square & $F$ value & $\operatorname{Pr}>F$ \\
\hline Model & 4 & 54.61528 & 13.65382 & 5.13 & 0.0106 \\
Error & 13 & 34.6225 & 2.663269 & & \\
Corrected total & 17 & 89.23778 & & & \\
\hline
\end{tabular}

Supplemental Table 2. Kentville, NS, Zone 6a, matted row, 2011 yield from 2010 planting. Mean separation with least significant difference (0.05).

\begin{tabular}{|c|c|c|c|c|c|}
\hline$\overline{\text { Cultivar }}$ & Spring plot fill $(0-4)$ & Marketable yield (t/ha) & Unmarketable yield (t/ha) & Berry wt (g) & Mean Julian harvest date \\
\hline Annapolis & $3.0 \mathrm{a}$ & $17.2 \mathrm{~b}$ & $1.6 \mathrm{~b}$ & $14.3 \mathrm{~b}$ & $184.2 \mathrm{c}$ \\
\hline AC Wendy & $2.2 \mathrm{~b}$ & $13.5 \mathrm{~b}$ & $2.0 \mathrm{~b}$ & $16.1 \mathrm{a}$ & $183.2 \mathrm{c}$ \\
\hline Jewel & $3.0 \mathrm{a}$ & $22.8 \mathrm{a}$ & $3.1 \mathrm{a}$ & $13.9 \mathrm{~b}$ & $192.7 \mathrm{a}$ \\
\hline Flavorfest & $2.6 \mathrm{ab}$ & $15.1 \mathrm{~b}$ & $1.9 \mathrm{~b}$ & $17.0 \mathrm{a}$ & $188.0 \mathrm{~b}$ \\
\hline
\end{tabular}

Subjective evaluation recorded good runner production and plant stand in matted-row production, and very juicy fruit with very good flavor.

Supplemental Table 3. Kentville, NS, Zone 6a, matted row, 2012 yield from 2011 planting. Mean separation with least significant difference (0.05).

\begin{tabular}{lccccc}
\hline Cultivar & No. reps & Marketable yield (t/ha) & Unmarketable yield (t/ha) & Berry wt (g) & Mean Julian harvest date \\
\hline Brunswick & 4 & $23.03 \mathrm{a}$ & $4.113 \mathrm{c}$ & $17.92 \mathrm{~b}$ & $182.9 \mathrm{a}$ \\
AC Wendy & 4 & $24.04 \mathrm{a}$ & $3.807 \mathrm{c}$ & $17.94 \mathrm{~b}$ & $178.3 \mathrm{~b}$ \\
Laurel & 4 & $17.29 \mathrm{~b}$ & $5.411 \mathrm{~b}$ & $15.62 \mathrm{c}$ & $183.4 \mathrm{a}$ \\
Flavorfest & 4 & $11.02 \mathrm{c}$ & $5.619 \mathrm{~b}$ & $19.52 \mathrm{a}$ & $183.0 \mathrm{a}$ \\
\hline
\end{tabular}

